\title{
Inspirational Muscle Training with Linear Device in Post-Operative Myocardial Revascularization: Systematic Review
}

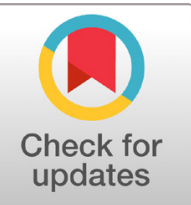

\begin{abstract}
Maria Gabriela da Silva Magalhães ${ }^{1}$, Cynara Letícia Ferreira Sacramento ${ }^{1}$, Monizze Rocha de Souza ${ }^{2}$ Vinícius Afonso Gomes ${ }^{3,4}$ and Sidney de Souza Oliveirar ${ }^{5,6 *}$
\end{abstract}

${ }^{1}$ Faculty of Science and Entrepreneurship (FACEMP), Santo Antônio de Jesus, Brazil

${ }^{2}$ Home Care Lifecoop, Santo Antônio de Jesus, Brazil

${ }^{3}$ University Salvador (UNIFACS), Salvador, Brazil

${ }^{4}$ University Ruy Barbosa (UNIRUY), Salvador, Brazil

${ }^{5}$ Metropolitan Union of Education and Culture (UNIME), Lauro de Freitas, Brazil

${ }^{6}$ Sidphysio - Cardiovascular, Respiratory and Metabolic Rehabilitation Clinic

*Corresponding author: Sidney de Souza Oliveira, Praça Renato Machado, Santo Antônio de Jesus, Bahia, Brazil.
Received Date: August 17, 2021

Published Date: August 31, 2021

\begin{abstract}
Cardiovascular diseases are considered one of the main causes of death in the world and one of the forms of treatment is cardiac surgery, including myocardial revascularization. After the good results, the surgery is related to pulmonary complications, causing respiratory muscle dysfunction, loss of muscle strength and decreased lung capacities and volumes. Physiotherapy uses several techniques and inspiratory muscle training emerges as a technique that aims to improve respiratory muscle strength and endurance. The aim of this study was to describe the effects and importance of inspiratory muscle training in the treatment of pulmonary dysfunction in the postoperative period of coronary artery bypass graft surgery. This is a systematic literature review, carried out with controlled and randomized clinical trials, indexed in the Cochrane Library, Lilacs, PEDro, Pubmed and SciELO databases, published between 2009 and July 2021 in Portuguese, English and Spanish. 08 articles make up this review. It was concluded that inspiratory muscle training, although there is no specific protocol on how to perform it, proved to be a safe, easy to apply and effective technique in the treatment of pulmonary dysfunctions and of paramount importance for rehabilitation in the postoperative period of revascularization of the myocardium.
\end{abstract}

Keywords: Myocardial revascularization; Breathing exercise; Endurance training; Physiotherapy techniques; Respiratory muscles; Breathing exercises; Respiratory therapy

\section{Introduction}

Cardiovascular diseases (CVD) are a group of diseases affecting the heart and blood vessels, constituting a major cause of death and hospitalization in the world [1]. Among the pathologies, there is coronary artery disease (CAD), characterized by the interruption of the blood supply to the heart through the coronary arteries, which constitutes a large index of deaths and hospital costs, with about 250 thousand hospitalizations and one thousand deaths in the year of 2015 [2,3]. Coronary artery bypass grafting (CABG) is one of the forms of treatment despite the good results may favor the emergence of various postoperative complications, pulmonary being among the most common and frequent $[4,5]$. These complications can be caused by factors such as use of extracorporeal circulation (ECC), anesthesia, thoracotomy or sternotomy, use of chest drains, patient hemodynamic status, type and duration of surgery, pain and application of pleural drains6, among other factors, that generate changes in lung volumes and capacities, as well as dysfunction of 
the respiratory muscles. These dysfunctions promote a reduction in lung volumes and capacities, changes in blood oxygenation values and, above all, reduction in chest expansion, favoring the development of atelectasis and pneumonia $[6,7]$.

Respiratory rehabilitation is increasingly being requested in order to prevent, minimize or reverse respiratory complications from cardiac surgery [7-9]. It has varying duration and frequency, depending on individual needs, preferences and institutional protocols. There are several techniques such as ventilatory patterns, incentive spirometry, deep breathing exercises, early ambulation, positioning, cough stimulation and inspiratory muscle training (IMT) with linear pressure, which is performed using a device with a predetermined pressure, where the patient performs inspirations against resistance, being the Threshold $₫$ IMT and POWERbreath $®$ the most used devices [7-10].

It is an easy-to-apply and extremely important technique in the postoperative period (PO) of patients undergoing CABG surgery, as it promotes muscle strengthening and increased functional capacity. Although there is still no specific protocol on how to perform the IMT, studies have shown it to be effective for the treatment of pulmonary disorders in the PO of cardiac surgery, some authors report a protocol that consists of using $30 \%$ to $40 \%$ of the inspiratory pressure maximum (MIP), with 3 sets of 10 repetitions and frequency from 01 to 02 times a day $[11,12]$. Intensive IMT using the Threshold $®$ IMT device with a linear load of $30 \%$ of the MIP, with progressive increase, promotes the strengthening and endurance of the respiratory muscles and, consequently, a reduction in the risk of developing respiratory complications [13]. Another linear load device used in TMI is the POWERbreath ${ }$, which through the resistance imposed by means of springs or an electronic valve, promotes an increase in respiratory muscle strength and endurance. The TMI with load from $50 \%$ of the PImax through POWERbreath $\AA$ is able to potentiate the effects of cardiac rehabilitation even applied for short training periods [14,15].

Because of the pulmonary dysfunction and its consequences caused the PO of patients undergoing CABG surgery, respiratory therapy through IMT, has been effective and widely used to improve the clinical condition of these patients. Therefore, this review aimed to understand the effects of applying IMT in the PO and describe the protocols used to improve respiratory muscle strength, functional capacity and quality of life of patients undergoing CABG surgery.

\section{Methodology}

The present study is characterized as a systematic literature review.

\section{Search strategy}

Performed with analytical and descriptive original articles published in indexed journals in databases Cochrane Library, Lilacs, PEDro, Pubmed and SciELO, from 2009 to July 2021, they were used in crossing the following keywords: Myocardial revascularization, Respiratory exercise, Endurance Training, Physiotherapy Techniques, Respiratory Muscles, Respiratory Therapy and its correlates in English and Spanish.

\section{Selection of studies}

To compose the results and discuss this study, the studies that met the inclusion criteria were selected: a) Original analytical and descriptive studies; b) published between 2009 and July 2021; c) studies that used IMT with a linear device as a form of intervention. The following were excluded: a) review articles, doctoral theses, master's dissertations, and case reports; b) studies that used patients undergoing combined CABG; c) studies that used IMT in the preoperative period; d) studies that did not describe the intervention carried out with the participants; e) duplicate studies.

\section{Research mechanism}

The review was developed by two independent authors who researched and evaluated the studies for inclusion. The results considered for the analysis of the effects of the influence of IMT on the treatment of pulmonary dysfunction in the postoperative period of CABG surgery were maximal inspiratory pressure (MIP), maximal expiratory pressure (MEP), expiratory flow pressure (PEF), tidal volume (VT), functional capacity, pulmonary function test and muscle strength test.

\section{Selection and data extraction}

In order to bring the findings closer to what the research proposed, the screening of studies was initially performed by applying the following filters: full text, randomized clinical trials, year of publication 2009 to July 2021, languages Portuguese, English and Spanish and after reading the titles, from that, the abstracts of the articles dealing with the proposed theme were read. After analyzing whether the articles met the research inclusion criteria, the studies were selected for full reading and reassessment of the proposed criteria. Finally, data extraction was performed according to the following criteria: a) author and year of publication, b) objective of the study, c) participants (number of individuals, age and sex), d) intervention and e) results.

\section{Quality assessment}

The methodological quality of the studies was assessed using the PEDro scale that even consisting of 11 criteria, only 10 are scored, as the first item (specifying the eligibility criteria) is not included in the total score, reaching the maximum score of 10 (range from 0 to 10). The mean PEDro score of the studies included in this review was 5 , as described in (Table 1 ).

\section{Result}

After crossing the descriptors and applying the filters through electronic search, at first 10,562 studies were found, with 4,895 in the Cochrane database, 131 in Lilacs, 845 in PEDro, 4,627 in PubMed 
and 64 in the SciELO database. From the delimitation of the filters, the analysis of the titles was carried out, remaining for full reading 27 potentially relevant studies. Of these, after reading the abstracts, 09 were excluded for not meeting the research eligibility criteria and 10 were excluded for being duplicates of other databases. In this context, after a complete reading of the selected studies, 08 articles make up this review, with 06 articles in English and 02 in Portuguese (Figure 1).

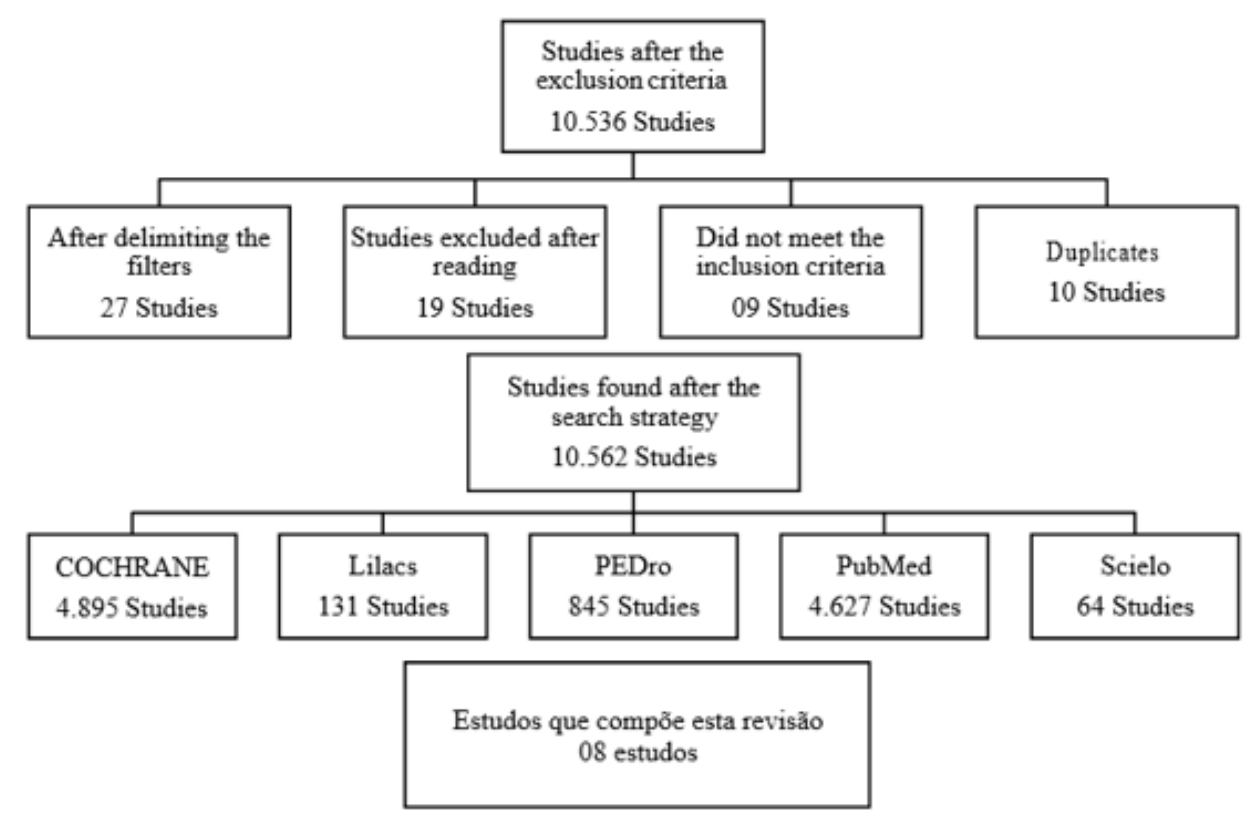

Figure 1: Flow chart of screening and selection of studies.

The 08 selected studies were evaluated on the PEDro scale according to the following criteria: 1 . specification of eligibility criteria (item not scored in the final score); 2 . random allocation of the sample; 3. blind distribution of people; 4 . similarity of groups; 5. blinding of the subjects participating in the study; 6 . blinding of those responsible for the intervention; 7. blinding of the evaluator;
8. measurement of at least one key outcome in $85 \%$ of the allocated subjects; 9. intention-to-treat analysis; 10. comparison between groups of at least one key outcome; 11 . The study presents both precision measures and variability measures for at least one key outcome. The studies selected and evaluated on the PEDro scale are shown in (Table 1).

Table 1: Presentation of the score of the selected articles, according to the PEDro scale.

\begin{tabular}{|c|c|c|c|c|c|c|c|c|c|c|c|c|}
\hline Reference & C1* & $\mathrm{C} 2$ & C3 & C4 & C5 & C6 & C7 & C8 & C9 & C10 & C11 & Score \\
\hline Barros, et al. [20] & 1 & 1 & 0 & 1 & 0 & 0 & 0 & 0 & 0 & 1 & 1 & $4 / 10$ \\
\hline Matheus, et al. [21] & 1 & 1 & 0 & 1 & 0 & 0 & 0 & 0 & 0 & 1 & 1 & $4 / 10$ \\
\hline Hermes, et al. [22] & 1 & 1 & 0 & 1 & 0 & 0 & 1 & 1 & 0 & 1 & 1 & $6 / 10$ \\
\hline Miozzo, et al. [25] & 1 & 1 & 1 & 1 & 0 & 0 & 0 & 0 & 0 & 1 & 1 & $5 / 10$ \\
\hline Santos, et al. [18] & 1 & 1 & 0 & 1 & 1 & 0 & 1 & 1 & 1 & 1 & 1 & $8 / 10$ \\
\hline Zanini, et al. [23] & 1 & 1 & 1 & 1 & 0 & 0 & 1 & 1 & 0 & 1 & 1 & $7 / 10$ \\
\hline Cordeiro, et al. [27] & 1 & 1 & 0 & 1 & 0 & 0 & 0 & 1 & 0 & 1 & 1 & $5 / 10$ \\
\hline Cordeiro, et al. [24] & 1 & 1 & 0 & 1 & 1 & 0 & 0 & 1 & 0 & 1 & 1 & $6 / 10$ \\
\hline
\end{tabular}

C: quality criterion on the PEDro scale; 0 : negative score for the criterion; 1 : positive score for the criterion. ${ }^{*}$ Criterion 1 is not computed in the final score.

\section{Participants}

There were a total of 288 participants in the 08 studies, with a mean age between 54 and 67 years, the majority being male. In 06 studies, 181 men and 89 women participated, and 01 study did not specify the gender of the included sample.

\section{Intervention}

Among the selected studies, 05 performed the intervention during the hospital period and 03 during the Cardiac Rehabilitation (CR) period, as follows: 02 started after weaning from invasive mechanical ventilation; 02 applied on the first PO day; 02 during 
the RC program, and; 01 applied in the PO, but did not specify the starting day. As for the equipment used in the intervention, 05 studies used the Threshold $₫$ IMT and 03 the POWERbreathe $₫$, The training protocols during the hospital period used initial pressures that ranged between $10 \%$ and $40 \%$ of MIP, the frequency performed ranged from 01 to 02 times a day and consisted of 03 sets ranging from 10 to 15 repetitions. The control group received conventional physical therapy according to the hospital routine.
In the studies carried out during the CR phase, 02 studies performed the initial training protocols using $50 \%$ of the MIP progressing over the weeks and the sessions lasted around 12 weeks. The control group received aerobic and resistance exercises. One study used a load of $30 \%$ of PImax performing 03 sets of 10 repetitions and only one study did not specify the load and duration of the training protocol. The main characteristics and results of the 08 studies used in this review are summarized in (Table 2).

Table 2: Clinical characteristics of the studies selected for this review.

\begin{tabular}{|c|c|c|c|c|}
\hline References & Objective & Sample and assessment & Intervention & Results \\
\hline Barros, et al. [20] & $\begin{array}{l}\text { To demonstrate the loss of } \\
\text { ventilatory capacity in the PO } \\
\text { in patients undergoing CABG } \\
\text { and demonstrate that the } \\
\text { TMR performed after surgery } \\
\text { can improve ventilatory capa- } \\
\text { city in this population. }\end{array}$ & $\begin{array}{c}\mathrm{CG}=15 \text { patients (mean age } 67 \\
\text { years); } \\
\mathrm{EG}=23 \text { patients (mean age } 62 \\
\text { years), undergoing CABG with ECC. } \\
\text { Assessment: MIP, MEP, dyspnea, } \\
\text { pain, PEF and CV. }\end{array}$ & $\begin{array}{c}\text { CG: Conventional physiothe- } \\
\text { rapy; } \\
\text { GE: Conventional physiothe- } \\
\text { rapy + TMR with Threshold } \\
\text { IMT®, with a load of } 40 \% \\
\text { of the PImax, in } 3 \text { sets of } 10 \\
\text { repetitions } 1 x / \text { day, during all } \\
\text { days of hospitalization in the } \\
\text { P0 period. }\end{array}$ & $\begin{array}{l}\text { TMR was effective in } \\
\text { restoring MIP, MEP, PEF } \\
\text { and CV. There were no di- } \\
\text { fferences between groups } \\
\text { with regard to days of } \\
\text { hospitalization, dyspnea } \\
\text { or pain. }\end{array}$ \\
\hline Matheus, et al. [21] & $\begin{array}{l}\text { Evaluate lung function and } \\
\text { respiratory muscle strength } \\
\text { and verify the effect of TMI } \\
\text { on measures of respiratory } \\
\text { muscle performance in the } \\
\text { PO of CABG } \\
\text { surgery. }\end{array}$ & $\begin{array}{c}\mathrm{CG}=24 \text { patients (mean age } 63 \\
\text { years); } \\
\mathrm{EG}=23 \text { patients (mean age } 61 \\
\text { years), diagnosed with chronic } \\
\text { coronary insufficiency and un- } \\
\text { dergoing CABG with CPB, through } \\
\text { median sternotomy. } \\
\text { Assessment: MIP, MEP, CV, VC and } \\
\text { PEF. }\end{array}$ & $\begin{array}{l}\text { CG: Conventional physiothe- } \\
\text { rapy; } \\
\text { GE: Conventional physiothera- } \\
\text { py and IMT with Threshold® } \\
\text { IMT } 02 x / \text { day with } 03 \text { sets of } \\
10 \text { repetitions with } 40 \% \text { of } \\
\text { MIP. }\end{array}$ & $\begin{array}{l}\text { IMT was effective in reco- } \\
\text { vering } \mathrm{CV} \text { and VC on the } \\
\text { 3rd PO day in the trained } \\
\text { group. }\end{array}$ \\
\hline Hermes, et al. [22] & $\begin{array}{l}\text { To investigate the short-term } \\
\text { efficiency of IMT associated } \\
\text { with combined aerobic and } \\
\text { resistance exercises in RMS, } \\
\text { functional capacity and QOL } \\
\text { in patients undergoing CABG } \\
\text { and in a phase II CR program. }\end{array}$ & $\begin{array}{c}\text { CRG = } 12 \text { patients (mean age } 59 \\
\text { years); } \\
\text { CRG + IMT = } 12 \text { patients (mean age } \\
55 \text { years), undergoing CABG and } \\
\text { the phase II CR program. } \\
\text { Assessment: MIP, MEP, VO2peak, } \\
\text { QL. }\end{array}$ & $\begin{array}{l}\text { CRG: Aerobic and resistance } \\
\text { training associated with dia- } \\
\text { phragmatic stimulation and } \\
\text { fractional breathing patterns; } \\
\text { CRG+IMT: Aerobic and } \\
\text { resistance training + IMT with } \\
\text { Threshold@ IMT in } 03 \text { sets of } \\
10 \text { repetitions with a load of } \\
30 \% \text { of the MIP. }\end{array}$ & $\begin{array}{l}\text { The CRG + IMT showed } \\
\text { improvement in MIP, MEP, } \\
\text { VO2peak and QL even in a } \\
\text { short training period. }\end{array}$ \\
\hline Miozzo, et al. [25] & $\begin{array}{l}\text { To evaluate the interaction } \\
\text { between high-intensity IMT } \\
\text { and aerobic exercise on phy- } \\
\text { sical capacity, RMS, periphe- } \\
\text { ral muscle strength and QoL } \\
\text { of patients undergoing CABG. }\end{array}$ & $\begin{array}{c}\text { AEG = } 9 \text { patients; } \\
\text { AEG + IMT = } 9 \text { patients, both with } \\
\text { a mean age of } 57 \text { years, under- } \\
\text { going elective CABG and CR. } \\
\text { Assessment: 6MWT, MIP, MEP, } \\
\text { peripheral muscle strength, QL, } \\
\text { VO2peak. }\end{array}$ & $\begin{array}{l}\text { EAG: Aerobic training for } 12 \\
\text { weeks with an average dura- } \\
\text { tion of } 40 \text { minutes; } \\
\text { EAG + IMT: High intensity IMT } \\
\text { with POWERbreathe® in } 05 \\
\text { sets with } 10 \text { repetitions and } \\
\text { load of } 50 \% \text { of the MIP until } \\
\text { the 8th week progressing to } \\
80 \% \text { until the end of the pro- } \\
\text { tocol + aerobic training. }\end{array}$ & $\begin{array}{c}\text { Both groups had signifi- } \\
\text { cant improvements in all } \\
\text { variables analyzed, howe- } \\
\text { ver, baseline characteris- } \\
\text { tics were similar between } \\
\text { groups. }\end{array}$ \\
\hline Santos, et al. [18] & $\begin{array}{l}\text { To investigate the effects } \\
\text { of IMT + moderate to high } \\
\text { intensity conventional } \\
\text { training on exercise capacity, } \\
\text { RMS, inspiratory muscle } \\
\text { endurance, QL and laboratory } \\
\text { biomarkers in patients after } \\
\text { CABG undergoing phase II } \\
\text { CR. }\end{array}$ & $\begin{array}{c}\text { IMT + CT = } 12 \text { patients (mean age } \\
55 \text { years); Sham-IMT = } 12 \text { patients } \\
\text { (mean age } 56 \text { years), undergoing } \\
\text { CABG and on the waiting list for } \\
\text { phase II of CR. } \\
\text { Assessment: VO2peak, 6MWT, MIP, } \\
\text { MEP, QL, } \\
\text { peripheral muscle strength, labo- } \\
\text { ratory biomarkers. }\end{array}$ & $\begin{array}{c}\text { IMT + CT = IMT with } \\
\text { POWERbreathe® } 2 \text { x/week } \\
\text { for } 12 \text { weeks with } 05 \text { sets of } \\
10 \text { repetitions with an initial } \\
\text { load of } 50 \% \text { of the MIP for } \\
2 \text { weeks, progressing in the } \\
\text { following weeks to } 80 \% \text { of the } \\
\text { MIP + aerobic and resistance } \\
\text { exercises. } \\
\text { Sham-IMT + CT = IMT with } \\
\text { POWERbreathe® in } 5 \text { sets of } \\
10 \text { repetitions with a constant } \\
\text { load of } 09 \text { cmH20 throughout } \\
\text { the protocol. }\end{array}$ & $\begin{array}{c}\text { The IMT + CT group } \\
\text { showed significantly } \\
\text { greater improvements in } \\
\text { VO2peak, 6MWT, MIP and } \\
\text { FRAP } \\
\text { compared to the sham- } \\
\text {-IMT } \\
\text { + CT group. }\end{array}$ \\
\hline
\end{tabular}




\begin{tabular}{|c|c|c|c|c|}
\hline Zanini, et al. [23] & $\begin{array}{l}\text { Evaluate the effects of diffe- } \\
\text { rent rehabilitation protocols } \\
\text { on the functional capacity } \\
\text { and pulmonary function of } \\
\text { patients undergoing CABG. }\end{array}$ & $\begin{array}{c}\text { G1 = } 10 \text { patients (mean age } 58 \\
\text { years); } \\
\text { G2 = } 10 \text { patients (mean age } 56 \\
\text { years); } \\
\text { G3 = } 10 \text { patients (mean age } 59 \\
\text { years); } \\
\text { G4 = } 9 \text { patients (mean age } 61 \\
\text { years) undergoing elective CABG } \\
\text { surgery. } \\
\text { Assessment: } 6 \mathrm{MWT}, \mathrm{FVC}, \mathrm{FEV} 1 \\
\text { MIP, MEP. }\end{array}$ & $\begin{array}{l}\text { G1: IMT with Threshold® IMT } \\
\text { + upper limb and lower limb } \\
\text { active exercise + progressive } \\
\text { early ambulation } \\
\text { + conventional physical } \\
\text { therapy; } \\
\text { G2: Upper and lower limb } \\
\text { active exercise + progressive } \\
\text { early ambulation + conventio- } \\
\text { nal physical therapy; } \\
\text { G3: IMT + conventional physi- } \\
\text { cal therapy; } \\
\text { G4: Conventional physiothe- } \\
\text { rapy. }\end{array}$ & $\begin{array}{l}\text { The baseline characteris- } \\
\text { tics were similar between } \\
\text { the groups and the use } \\
\text { of IMT Threshold® not } \\
\text { appear to influence the } \\
\text { variability of MIP in the } \\
\text { groups submitted to IMT. }\end{array}$ \\
\hline Cordeiro, et al. [27] & $\begin{array}{l}\text { To investigate whether IMT } \\
\text { based on the anaerobic } \\
\text { threshold modifies heart rate } \\
\text { and inspiratory muscle stren- } \\
\text { gth in patients undergoing } \\
\text { CABG. }\end{array}$ & $\begin{array}{l}\text { IMT-C }=21 \text { patients (mean age } 62 \\
\text { years) } \\
\text { IMT-LA = } 21 \text { patients (mean age } 61 \\
\text { years), undergoing CABG with CPB } \\
\text { and median sternotomy. } \\
\text { Assessment: MIP, MEP, VC, PEF, } \\
\text { 6MWT, length of hospital stay. }\end{array}$ & $\begin{array}{l}\text { IMT-C: IMT with PowerBrea- } \\
\text { the® with } 40 \% \text { of MIP in } 03 \\
\text { sets with } 15 \text { repetitions, } 02 x / \\
\text { day until hospital discharge. } \\
\text { IMT-LA: IMT based on AT with } \\
\text { a load of } 10 \% \text { of MIP increa- } \\
\text { sing until the patient is unable } \\
\text { to continue, in } 03 \text { sets with } \\
15 \text { repetitions, } 02 x / \text { day until } \\
\text { hospital discharge. }\end{array}$ & $\begin{array}{l}\text { The IMT based on AL was } \\
\text { able to minimize the loss } \\
\text { of HR and IMS and reduce } \\
\text { the length of stay in pa- } \\
\text { tients undergoing CABG. }\end{array}$ \\
\hline Cordeiro, et al. [24] & $\begin{array}{l}\text { To investigate whether the } \\
\text { IMT with a linear pressure } \\
\text { load device is superior to } \\
\text { the inspiratory incentive in } \\
\text { the functional capacity and } \\
\text { muscle strength of patients } \\
\text { undergoing CABG. }\end{array}$ & $\begin{array}{c}\mathrm{CG}=19 \text { patients (mean age } 57 \\
\text { years). GTMI }=19 \text { patients (mean } \\
\text { age } 55 \text { years). } \\
\text { GII = } 18 \text { patients (mean age } 54 \\
\text { years). } \\
\text { Assessment: MIP, MEP, PEF, 6MWT } \\
\text { and FIM. }\end{array}$ & $\begin{array}{l}\text { CG: ambulation, breathing } \\
\text { exercises, cycle ergometry and } \\
\text { kinesiotherapy; IMTG: IMT } \\
\text { with Threshold IMT® with a } \\
\text { load corresponding to } 40 \% \\
\text { of MIP, performing 03 sets of } \\
10 \text { repetitions, } 02 \text { times a day } \\
\text { until hospital discharge. } \\
\text { IG: Training with the ins- } \\
\text { piratory flow stimulator, } \\
\text { performing maneuvers with } \\
\text { deep inspirations and with } \\
\text { the highest peak inspiratory } \\
\text { flow possible, aiming to reach } \\
\text { a load equivalent to } 50 \% \text { of } \\
\text { MIP, with } 30 \text { inspirations and } \\
02 \text { times a day until hospital } \\
\text { discharge. }\end{array}$ & $\begin{array}{l}\text { There was a significant } \\
\text { reduction in all variables, } \\
\text { in relation to MIP, IMT had } \\
\text { a higher value in the PO; } \\
\text { The same behavior was } \\
\text { observed in MEP; } \\
\text { In relation to the 6MWT, } \\
\text { there was less loss in the } \\
\text { IMT. }\end{array}$ \\
\hline
\end{tabular}

AEG: Aerobic Exercise Group; AL: Anaerobic Preliminary; CABG: Myocardial Revascularization; APDA: Antioxidant Power Determination Assay; CG: Control Group; CmH2O: Centimeters of Water; CR: Cardiac Rehabilitation; CRG: Cardiac Rehabilitation Group; CRP: cardiorespiratory rehabilitation program; CT: Combined Training; CV: Current Volume; ECC: Extracorporeal circulation; EG: Experimental Group; FIM: Functional Independence Measure; FVC: Forced Vital Capacity; FEV1: forced expired volume of first second; G1: Group 1; G2: Group 2; G3: Group 3; G4: Group 4; HR: Heart Rate; IG: Intervention Group; IIG: Inspiratory Incentive Group; IMS: Inspiratory Muscle Strength; IMT: Inspiratory Muscle Training; IMT-C: Inspiratory-Conventional Muscle Training; IMTG: Inspiratory Muscle Training Group; IMT-LA: Anaerobic Threshold Based Inspiratory Muscle Training; MEP: Maximum Expiratory Pressure; MIP: Maximum Inspiratory Pressure; MMII: Lower limbs; MMSS: Superior Members; PO: Postoperative; POWERbreathe $\AA_{0}$ : High-tech Respiratory Muscle Training Device; QL: Quality of Life; RMS: Respiratory Muscle Strength; RMT: Respiratory Muscle Training; SatO ${ }_{2}$ : oxygen saturation; Sham-TMI: False-TMI; 6MWT: 6-Minute Walk Test; Threshold IMT®: Linear Pressure Device for Inspiratory Muscle Training; $\mathbf{V O}_{2}$ peak: peak oxygen consumption; VC: Vital Capacity.

\section{Discussion}

Even with attempts to minimize the deleterious effects on lung function, patients undergoing cardiac procedures often experience respiratory system dysfunction such as reduced lung function, inspiratory muscle strength, peak expiratory flow with lung function tending to remain from 25 to $30 \%$ lower even after 03 and a half months after surgery16. Other authors have already demonstrated that IMT is a safe and viable resource for the rehabilitation of patients in the Intensive Care Unit, regardless of whether they are on invasive mechanical ventilation, helping to gain strength in the inspiratory muscles, especially in diaphragm activation, improving lung function, functional capacity and, consequently, their quality of life [17-19].

By presenting a decrease in parameters such as MIP, MEP, PEF and $\mathrm{CV}$, physiotherapy through respiratory muscle training (RMT) proves to be effective in promoting the reestablishment of these parameters and optimizing the clinical picture of these patients [20-22]. Of the analyzed studies, 05 used the linear resistor Threshold $®$ IMT oscillating from 01 to 03 daily sessions with an adjusted load of up to $45 \%$ of the MIP and 03 studies used the linear resistor POWERbreath $\AA$ with a protocol time of around 12 weeks and a load of up to $80 \%$ of MIP. 
Aiming to demonstrate that the IMT performed in the PO of CABG surgery could improve VC, Barros, et al. [20] evaluated 23 patients with a mean age of 62 years and used the IMT with Threshold® IMT in 3 sets of 10 repetitions, 01 times a day, with $40 \%$ of MIP until hospital discharge and found that this protocol was effective in improving MIP, MEP, PEF and CV in the studied population when compared to the control group that underwent only conventional physical therapy. Similar results were found by Matheus, et al. [21] that aiming to evaluate the effects of TMI with Threshold $®$ IMT on the performance of respiratory muscles in the PO of CABG, evaluated 23 patients with a mean age of 61 years with the protocol consisting of 3 series with 10 repetitions, twice a day, with $40 \%$ of MIP, after the intervention, it found significant improvements in MIP, MEP, CV, VC and PEF on the 3rd PO day in the studied group. Reinforcing the idea that TMI using Threshold ${ }^{\circledR}$ IMT improves some variables, Hermes, et al. [22] investigated the efficacy of short-term IMT associated with combined aerobic and resistance exercises, for this they submitted 12 patients with a mean age of 55 years to IMT using the Threshold® IMT to the protocol containing 3 sets of 10 repetitions, with a load of $30 \%$ of the MIP, the results showed improvement in MIP, MEP, V02peak and QL. Corroborating the studies already reported, Zanini, et al. [23], when evaluating the effects of various rehabilitation protocols, found that patients undergoing IMT with the use of Threshold ${ }^{\circledR}$ IMT had an increase in MIP, MEP, FLC, distance covered in the 6MWT and increase in V02Peak after 30 days of training, but the results indicated in their study regarding the outcome of lung capacity, showed that it was not possible to observe changes in the variability of the MIP values of the two groups that underwent the intervention compared to the groups that did not undergo IMT. All groups showed a decline in pulmonary functions in the immediate postoperative period, however, 30 days after hospital discharge, the values of all groups were similar to those obtained in the preoperative period, with no significant difference in the variables analyzed between the groups. Although the sample was homogeneous, the load and duration of the IMT protocol was not specified. In the most recent study, with the objective of verifying which type of IMT device is most effective in reducing the impact on functional capacity, pulmonary complications, functionality, pulmonary function and length of hospital stay, Cordeiro, et al. [24] compared the Threshold IMT® with the flow booster, the results showed that a IMT program using a linear pressure load device (Threshold IMT $®$ ) with a load corresponding to $40 \%$ of the MIP, performing 03 sets of 10 repetitions, 02 times a day until hospital discharge was superior to flow stimulator to minimize the loss of functional capacity, reduce postoperative complications and decrease functionality and worsen lung function, especially inspiratory muscle strength, and shorten the time of permanence of this population studied.

Although the articles that used the Threshold® IMT linear resistor did not apply a specific protocol, and each study adopted a different method, all had an improvement in the OP when compared to the control group. Barros, et al. [20] evaluated the ventilatory capacity in the PO of CABG surgery and described that the measurements of MIP, MEP, TV and peak expiratory flow had a significant decrease on the first PO day in both groups, but the variables in the group that underwent respiratory muscle training returned to baseline preoperative values at discharge. The role of the physiotherapist in the PO of CABG is quite extensive and effective, through the IMT with the use of linear pressure devices, it can bring improvements and benefits in the ventilatory and functional capacity of these patients, whether in the hospital or convalescent period.

The POWERbreath ${ }^{\circledR}$ (HaBLtd, UK) is another device used in TMI, it uses resistance imposed by means of springs or an electronic valve, promoting an increase in respiratory muscle strength and endurance. It is a specific portable device for IMT improves inspiratory muscle function in healthy patients or those with respiratory dysfunction, including decreased inspiratory muscle strength. The equipment uses a fast-response and/or electronically controlled valve that generates resistance to inspiration and training against this resistance makes the inspiratory muscles stronger and more resistant to fatigue. Adaptation to dynamic changes in respiratory muscle strength occur during breathing, and can adapt automatically at the beginning of each session treatments [12].

Therefore, Miozzo, et al. [25] test that their study was the first to assess the association of the use of high-intensity IMT with aerobic exercise in the PO of patients undergoing CABG. Despite observing significant improvements in all evaluated outcomes, it found that there were no additional gains. This result is due to the fact that it was necessary to increase the sample and a control group that did not perform any type of intervention, so that the results could be compared more effectively. The study evaluated the interaction between high-intensity IMT and aerobic exercise in patients between the 14th and 30th postoperative day. After 12 weeks of intervention, he found that baseline characteristics were similar between groups and that there were no significant differences between the group that performed only aerobic exercise and the group that performed the intervention with the IMT. There was an improvement in all the variables analyzed in both groups, however, even in their study, the IMT was not able to provide additional benefits in most of the variables analyzed, it was possible to observe results in the inspiratory muscle strength.

On the other hand, the results obtained in the study by Santos, et al. [26] when performing IMT + aerobic and resistance training, found that the IMT provided significantly greater improvements and additional benefits in exercise capacity, inspiratory muscle strength, QL and antioxidant profile in patients undergoing the 
intervention protocol. For Santos, et al. [26] who investigated the effects of IMT + moderate to high intensity combined training on exercise capacity, respiratory muscle strength, inspiratory muscle resistance, quality of life and laboratory biomarkers in patients in the PO of CABG surgery undergoing phase II of the cardiac rehabilitation program, submitted 12 patients with a mean age of 55 years to IMT with the use of POWERbreathe ${ }^{\circledR} 02$ times a week for 12 weeks with 5 sets of 10 repetitions with an initial load of $50 \%$ of the MIP for 2 weeks, progressing in the following weeks up to $80 \%$ of MIP + aerobic and resistance exercises, the results showed that there were significant improvements in VO2peak, 6MWT, MIP and MEP. Cordeiro's study by Santos, Cordeiro, et al. [27] started the training protocol on the first PO day until hospital discharge in the two intervention groups, both groups were trained with the POWERbreath ${ }^{\circledR}$ linear load device, performing 3 series with 15 repetitions 2 times a day. The IMT-conventional group was submitted to a load of $40 \%$ of the MIP and the IMT group based on the anaerobic threshold (IMT-LA), after being submitted to exercises according to the glycemic threshold, was trained using an initial load of $10 \%$ of MIP increasing the load until the patient was unable to continue. This load increase was performed from the capillary blood glucose assessment assessed at the end of each load increase. Despite a similar protocol between the groups in your study, it was found that the patients in the IMT-LA group used a lower load than the IMT-conventional group as they had a threshold of $20 \%$ of MIP and the limit of these patients was reached in around $35 \%$ of the increased load. There was a reduction in the loss of the IMF, functional capacity and length of hospital stay in the group undergoing IMT-LA.

The use of the Powerbreathe ${ }^{\circledR}$ device in hospital and intensive care settings has been the subject of research by several physiotherapists and the results can bring important benefits to patients. The IMT with load from $50 \%$ of the PImax through POWERbreath ${ }^{\circledR}$ is able to potentiate the effects of cardiac rehabilitation even applied for short training periods.

\section{Conclusion}

In the present study, the IMT with the use of linear devices such as the Threshold ${ }^{\circledR}$ IMT and the POWERbreath $\AA$, proved to be beneficial, showing positive results and clinical improvement of the analyzed variables, regardless of the protocol used. The results presented in this review show the beneficial effects of IMT in the PO of CABG, being a safe technique, easy to apply and capable of promoting improvements in several parameters, contributing to the improvement of clinical and functional aspects and reduction of pulmonary complications resulting from surgery. However, there is not yet in the literature, many scientific evidence indicating that load better, sets, reps, and frequencies to be applied, either the physiological effects on the muscles involved in the inspiratory process. Thus, further studies are needed to better define the ideal principles of their application and standardizing protocols for performing IMT in these patients.

\section{Author contributions}

Magalhães MGS and Oliveira SS conceived the study and research design. Magalhães MGS, Sacramento CLF, Oliveira SS, Gomes VA e Rocha MS analyzed and interpreted the data. Magalhães MGS, Gomes VA and Oliveira SS wrote the manuscript. Oliveira SS critically reviewed the manuscript for important intellectual content.

\section{Acknowledgement}

None.

\section{Conflict of Interest}

No conflict of interest.

\section{References}

1. Kaufman R, Azevedo VMP, Sá RMG, Geller M, Xavier RMA, et al. (2018) Epidemiological characteristics and predictors of mortality in patients over 70 years of age undergoing surgical myocardial revascularization. Int J Cardiovasc Sci 31(3): 258-263.

2. Lobato PHM, Junior FMV, Nunes MBG, Galucio VAQL, Barreto EL (2019) Clinical course of patients undergoing myocardial revascularization surgery in a public cardiology referral hospital in Pará, Brazil. Int J Cardiovasc Sci 32(3): 217-226.

3. Caeres E, Nunes CP (2019) Coronary artery disease: treatments and their indications. Rev Med Family Health Ment 1(1): 144-123.

4. Beccaria LM, Cesarino CB, Werneck AL, Correio NCG, Correio KSS, et al. (2015) Postoperative complications in patients undergoing cardiac surgery in a teaching hospital. Health Science Arch 22(3): 37-41.

5. Cani KC, Bonorino KC, Gulart AA, Palú M, Karloh M, et al. (2018) Pulmonary complications after coronary artery bypass graft surgery: associated factors. ASSOBRAFIR Science 8(2): 41-50.

6. Lívia Arcêncio, Marilize Diniz de Souza, Bárbara Schiavon Bortolin, Adriana Cristina Martinez Fernandes, Alfredo José Rodrigues, et al. (2018) Pre-and postoperative care in cardiothoracic surgery: a physiotherapeutic approach. Rev Bras Cir Cardiovasc 23(3): 400-410.

7. Morsch KT, Leguisamo CP, Camargo MD, Coronel CC, Mattos W, et al. (2009) Ventilatory profile of patients undergoing CABG surgery. Rev Bras de Cir Cardiovasc 24(2): 180-187.

8. Cavenaghi S, Ferreira LL, Marino LHC, Lamari NM (2011) Respiratory physiotherapy in the pre- and postoperative period of coronary artery bypass graft surgery. Rev Bras Cir Cardiovasc 26 (3): 455-451.

9. Miranda RCV, Padulla SAT, Bortolatto CR (2011) Respiratory physiotherapy and its applicability in the preoperative period of cardiac surgery. Rev Bras Cir Cardiovasc 26(4): 647-652.

10. Pedrosa R (2016) Effect of inspiratory muscle training with different loads on respiratory muscle strength and function.

11. Souza E, Terra ELSV, Pereira R, Chicayban L, Silva J, et al. (2008) Electromyographic analysis of inspiratory muscle training under different Threshold IMT loads. Rev Perspec Online 2(7): 103-112.

12. Kulkarni SR, Fletcher E, McConnell AK, Poskitt KR, Whyman MR (2010) Pre-operative inspiratory muscle training preserves postoperative inspiratory muscle strength following major abdominal surgery - a randomized pilot study. Ann R Coll Surg Engl 92: 700-707.

13. Feltrim MIZ, Jatene FB, Bernado WM (2007) In high-risk patients undergoing myocardial revascularization, preoperative respiratory 
physiotherapy prevents pulmonary complications. Rev Assoc Med Bras 53(1): 8-9.

14. Júnior BRBN, Gómez TB, Neto MG (2016) Use of Powerbreathe $\AA$ in inspiratory muscle training for athletes: systematic review. Fisioter Mov 29(4): 821-830.

15. Fortes JVS, Borges MGB, Marques MJS, Oliveira RL, et al. (2021) Effects of Inspiratory Muscle Training Using an Electronic Device on Patients Undergoing Cardiac Surgery: A Randomized Controlled Trial. Int J Cardiovasc Sci 34(1): 44-52.

16. Ferreira GM, Haeffner MP, Barreto SSM, Dall Ago P (2010) Incentive spirometry with positive expiratory pressure is beneficial after myocardial revascularization. Arq Bras Cardiol 94(2): 246-251.

17. Bissett B, Leditschke IA, Green M, Marzano V, Collins S, et al (2019) Inspiratory muscle training for intensive care patients: A multidisciplinary practical guide for clinicians. Aust Crit Care 32(3): 249-255.

18. Walterspachera S, Pietschc F, Walkera DJ, Rockerd K, Kabitza HansJoachim (2018) Activation of respiratory muscles during respiratory muscle training. Resp Phys Neurobiol 247: 126-132.

19. Elkins M, Dentice R (2015) Inspiratory muscle training facilitates weaning from mechanical ventilation among patients in the intensive care unit: A systematic review. J Physiother 61(3): 125-134.

20. Barros GF, Santos CS, Granado FB, Costa PT, Límaco RP, et al. (2010) Respiratory muscle training in myocardial revascularization. Rev Bras Cir Cardiovasc 25(4): 483-490.

21. Matheus GB, Dragosavac D, Trevisan P, Costa CE, Lopes MM, et al (2012) Muscle training improves tidal volume and vital capacity in the postoperative period of myocardial revascularization. Rev Bras Cir Cardiovasc 27(3): 362-369.
22. Hermes BM, Cardoso DM, Gomes TJN, Santos TD, Vicente MS, et al. (2015) Short-term inspiratory muscle training potentiates the benefits of aerobic and resistance training in patients undergoing CABG in phase II cardiac rehabilitation program. Rev Bras Cir Cardiovasc 30(4): 474 481.

23. Zanini M, Nery RM, Lima JB, Buhler RP, Silveira AD, et al. (2019) Effects of different rehabilitation protocols in inpatient cardiac rehabilitation after coronary artery bypass graft surgery: a randomized clinical trial. J Cardiopulm Rehabil Prev 39(6): E19-E25.

24. Cordeiro ALL, Soares LO, Vasconcelos MLL, Correia TRP, Souza AS, et al. (2021) Two types of inspiratory muscle training on muscle strength in patients submitted to coronary artery bypass grafting: clinical trial. Filister Bras 22(3): 290-305.

25. Miozzo AP, Stein C, Marcolino MZ, Sisto IR, Hauck M, et al. (2018) Effects of High-Intensity Inspiratory Muscle Training Associated with Aerobic Exercise in Patients Undergoing CABG: Randomized Clinical Trial. Braz J Cardiovasc Surg 33(4): 376-383.

26. Santos TD, Pereira SN, Portela LOC, Cardoso DM, Lago PD, et al. (2019) Moderate-to-high intensity inspiratory muscle training improves the effects of combined training on exercise capacity in patients after coronary artery bypass graft surgery: A randomized clinical trial. Int J Cardiovasc 279: 40-46.

27. Cordeiro ALL, Silva LGR, Pinto MO, Araújo JS, Guimarães AR, et al. (2020) Behavior of pulmonary function after hospital discharge in patients submitted to myocardial revascularization. Int J Cardiovasc Sci 32(2): 104- 109 